\title{
On the foreign exchange risk premium in a general equilibrium model
}

\author{
Charles Engel* \\ Department of Economics, University of Washington, Seattle, WA 98195, USA \\ Received October 1990, revised version received May 1991
}

The foreign exchange risk premium in a cash-in-advance model is investigated. Some weaknesses of the definition of the risk premium generally used are discussed. It is shown that the primary ultimate source of foreign exchange risk is the covariance of monetary shocks with real output shocks. Several studies have assumed this covariance is zero, and hence assumed away the major source of risk in the model. Finally, the risk premium generated from standard versions of this model is argued to be very small, because it is the same order of magnitude as covariances of money and output growth rates.

\section{Introduction}

One interpretation of the vast empirical literature that documents the failure of the hypothesis that the forward exchange rate is an unbiased predictor of the future spot exchange rate is that there is a sizable timevarying foreign exchange risk premium. While there are other possible explanations of this failure that essentially rest on some sort of market inefficiency [see Froot (1990) for a review], a considerable effort has been undertaken in recent years to demonstrate that risk premiums generated from general equilibrium cash-in-advance models [models related to Lucas (1982)] offer a potential explanation for this empirical result. ${ }^{1}$ Much of this literature appears to ignore the findings of Stulz (1984) in a somewhat different type of general equilibrium model that a primary source for foreign exchange risk is the covariance of money growth with real output growth.

\footnotetext{
*The author wishes to thank David Backus, Toni Braun, Fabio Canova, Jon Eaton, Jeff Frankel, Ken Froot, Craig Hakkio, Jim Hamilton, Robert Hodrick, Len Mirman, Maurice Obstfeld and Ann Sibert for useful comments. The first version of this paper was written at the University of Virginia. The revision was completed while the author was a Visiting Scholar at the Federal Reserve Bank of Kansas City. The views expressed in this paper are not necessarily shared by the Federal Reserve Bank of Kansas City or the Federal Reserve System.

${ }^{1}$ See Domowitz and Hakkio (1985), Hodrick and Srivastava (1986), Kaminsky and Peruga (1988), Hodrick (1989a), Boyle (1990) and Canova and Marrinan (1990). Related papers with a different set-up are Sibert (1989), Backus, Gregory and Telmer (1990) and Hakkio and Sibert (1990).
} 
Indeed, much of the recent literature assumes the stochastic processes for money and real shocks are independent.

This paper demonstrates that foreign exchange risk in cash-in-advance Lucas-style models is derived mainly from the covariances of money growth shocks with real output growth shocks. Furthermore, as in Stulz (1984), the size of the risk premiums is approximately the same size as these covariances. It is argued that plausible estimates of the size of these covariances are very much smaller than the risk premiums that need to be explained.

It may seem puzzling that the recent literature has widely assumed independence of monetary and real shocks, since they are a critical mechanism for generating risk premiums. The proximate cause is that this literature has not incorporated the results of research which has argued that $F_{t}-$ $\mathrm{E}_{t} S_{t+1}$ is not an appropriate measure of the foreign exchange risk premium, where $F_{t}$ is the one-period ahead forward rate expressed as domestic currency per unit of foreign currency, and $S_{t}$ is the spot exchange rate. The problems with this definition, and a more plausible alternative, have been discussed by Boyer (1977), Krugman (1977), Stockman (1978), Frankel (1979), Frenkel and Razin (1980), Engel (1984), and Sibert (1989). Part of the reason for this oversight may be that there is no rigorous discussion in the literature of the assumptions needed to arrive at a foreign exchange risk premium in a multi-good world. Section 2 of this paper contains such a discussion. While the material of section 2 is ancillary to the central argument of this paper, it provides necessary background for the inferences of subsequent sections.

Section 3 demonstrates the relation of the risk premium to the stochastic processes of the exogenous variables in the Lucas model. It shows that covariances of domestic and foreign monetary shocks with domestic and foreign real shocks are the chief ultimate source of risk in this model. Subsection 3.1 shows that the assumptions made in some of the papers that have used the Lucas model imply that the appropriately measured risk premium in their versions of the model is actually zero. Clearly this result went unrecognized because the papers did not use the definition of the risk premium advocated in section 2 .

Section 4 concludes by showing, with an approximation, that the risk premium from the Lucas model is apt to be very small.

\section{The foreign exchange risk premium}

In the foreign exchange literature the notion of a risk premium reflected in the forward rate is taken to mean the difference between the actual forward rate, and what it would be if agents were risk neutral. This is an extremely useful concept, since it has empirical content which can shed light on the importance of risk aversion in international financial markets. The degree of 
risk aversion of agents is important, for example, in determining the usefulness of sterilized intervention or perhaps in deciding the relative virtues of fixed versus floating exchange rate systems.

This definition of a risk premium requires that we know what the forward rate would be if investors were risk neutral, which in turn requires us to know what it means to be risk neutral in a many-commodity world. There is an extensive literature that discusses ways of measuring the degree of risk aversion when there are many goods. Stiglitz (1969) discusses in detail exactly the case we are interested in - risk neutrality. He shows that if consumers have utility that is linear homogeneous, their behavior captures those properties we tend to associate with risk neutrality. We restrict attention here to the felicity or period utility function of individuals with time-separable utility.

In the single-good case an agent with von Neumann-Morgenstern preferences is considered to be risk averse if he has concave utility, and risk neutral if he has linear utility. In the many-good case, risk-averse agents have concave utility, but it seems too restrictive to insist that risk-neutral agents have utility that is linear in all goods. That would imply, for example, that all goods were perfect substitutes.

Carrying the analogy further, in the single-good case a risk-neutral agent is indifferent between a fair gamble and its certainty equivalent. That seems too strong a requirement in the many-good case. It would rule out convex indifference curves. The certainty equivalent of a gamble whose two prizes lay on the same convex indifference curve would yield greater utility than either of the prizes. Rejection of this gamble does not appear to be evidence of risk-averse behavior.

Instead, one might consider only gambles that offer scalar multiples of a given set of goods as prizes. Indifference between all fair gambles of this type or their certainty equivalents will constitute risk-neutral behavior. It is a simple exercise to show that this definition requires that risk-neutral investors have utility that can be expressed as an affine transformation of a linear homogeneous function.

One implication is that the risk-averse investors that we can study should have utility that is a concave transformation of a linear homogeneous function - that is, their utility must be homothetic. Only then can we reasonably ask what the forward rate would be if investors were risk neutral. In that case, utility can be written as $U=V(h(x))$, where $x$ is the vector of consumption goods, and $h$ is a linear homogeneous function. To arrive at what this person's utility would be if he were risk neutral, we take the 'least concave representation' of $U$. In this case, the least concave representation is simply $h(x)$.

There is a very natural analog to the single-good case in which we define a risk-neutral person as being one whose utility can be represented as an affine 
transformation of his level of consumption. The homothetic utility function $V(h(x))$ yields an indirect utility function of the form $V(Z / P)$, where $Z$ is the individual's nominal expenditure, and $P$ is a linear homogeneous function of prices that can be thought of as a price index. When $U$ is linear homogeneous, $V$ is linear. Hence, in the multi-good setting, a risk-neutral individual has a direct utility function that is linear homogeneous, and an indirect utility function that can be expressed as an affine transformation of 'real' expenditure.

A simple example of a homothetic utility function is $V\left(C_{1}^{\alpha} C_{2}^{1-\alpha}\right)$, where $V^{\prime}>0, V^{\prime \prime}<0$, and $C_{i}$ represents consumption of good $i$. For this utility function, $h(\cdot)$ is given by $C_{1}^{\alpha} C_{2}^{1-\alpha}$. The price index is then proportional to $P_{1}^{\alpha} P_{2}^{1-\alpha}$, where $P_{i}$ is the nominal price of good $i$.

These results apparently have not been entirely incorporated in studies of the foreign exchange risk premium, since Domowitz and Hakkio (1985) and Hodrick and Srivastava (1986) both assume risk-neutral investors (investors with linear homogeneous utility) in their studies of the consequences of riskaverse behavior for the forward rate.

If all individuals have preferences that are identical but not homothetic, then in general it would not be possible to define the risk premium as above. There would arise inevitably the confounding of effects on the forward rate that are attributable to risk aversion, and effects that arise because individuals have different marginal rates of substitution at identical prices but different levels of expenditure.

To illustrate this point, consider the study of Hodrick (1989a) which investigates the behavior of the deviation of $\log \left(F_{t}\right)$ from $E_{t} \log \left(S_{t+1}\right)$ in a cash-in-advance model inspired by Svensson $(1985 \mathrm{a}, \mathrm{b})$. It should not be possible to define the foreign exchange risk premium in his model, because his investors have utility functions that are not homothetic. (The investors' utility functions are given by $[1 /(1-\gamma)] C_{1}^{1-\gamma}+[1 /(1-\delta)] C_{2}^{1-\delta}$.) It is clear that investors in Hodrick's model are risk averse (because utility is strictly concave), but it is not clear how to separate out how much of the level of the forward rate can be attributed to risk aversion.

In contrast, there is a very clear measure of the foreign exchange risk premium when agents have homothetic utility. Under fairly general conditions (which include the assumptions of the Lucas model, as we will see in section 3), when agents are risk neutral, we can derive

$$
F_{t}=\frac{\mathrm{E}_{t}\left(S_{t+1} / P_{t+1}\right)}{\mathrm{E}_{t}\left(1 / P_{t+1}\right)}
$$

$F_{t}-\mathrm{E}_{\mathrm{t}} S_{t+1}$ is not the difference between the forward rate and what it would be if individuals were risk neutral, and so cannot be called a 'risk 
premium'. Moreover, even when investors are risk neutral, it is non-zero and will vary as prices and exchange rates change [see Engel (1984)]. It would satisfy the notion of a risk premium if investors had money illusion, so that utility was not a function of goods, but instead a function of the nominal value (in terms of the domestic currency) of consumption. However, this type of utility function cannot be derived from the usual axioms about consumers' preferences, so we must reject $F_{t}-\mathbf{E}_{t} S_{t+1}$ as an acceptable measure of the risk premium.

Define $\Phi_{t}$ as the value that the forward rate would take on if investors were risk neutral:

$$
\Phi_{t} \equiv \frac{\mathrm{E}_{t}\left(S_{t+1} / P_{t+1}\right)}{\mathrm{E}_{t}\left(1 / P_{t+1}\right)}
$$

The natural measure of the risk premium is the difference between $F_{t}$ and $\Phi_{t}$, since it is the difference between the forward rate and what the forward rate would be in the presence of risk-neutral investors. ${ }^{2}$ As discussed above, this approach suggests that it would not be possible to measure a risk premium when investors' utility is not homothetic. In practice, one might approximate the risk premium by 'taking a stand on how to measure the purchasing power of the dollar' [quoting Hodrick's (1987, p. 68) discussion of my earlier paper]. This would entail choosing a consumer price index, $P$, to use in any empirical implementation.

\section{The risk premium in a Lucas model}

This section considers a two-country general equilibrium model of the Lucas (1982) type. A detailed derivation of basic asset pricing relations will not be included, since those derivations are readily available in Lucas and related papers.

In the model we investigate here, there are two countries populated by individuals with identical homothetic preferences. There are two goods - one produced at home, and one produced abroad. Individuals have infinite horizons. An individual who lives in the home country was endowed at the beginning of time with a claim to a stream of income of $\varepsilon_{t}^{0}$ every period. The stream $\varepsilon_{\mathrm{t}}^{0}$ is stochastic, and follows a Markov process. The individual in the home country also receives a transfer of the home currency each period. The size of the transfer of currency also is stochastic and follows a Markov process.

\footnotetext{
${ }^{2}$ Note that $F_{t}-\Phi_{1}$ and $F_{t}-E_{t} S_{t+1}$ might even have different signs depending on the joint distribution of prices and exchange rates [and, in the simulations of Hakkio and Sibert (1990) often do have different signs]. This is another indication of the difficulties of $F_{t}-\mathrm{E}_{t} S_{t+1}$ as a measure of the risk premium.
} 
Individuals in the foreign country differ from individuals in the home country in that they have a claim to a stream of goods, $\varepsilon_{t}^{1}$ every period, that is a different type of good than is received by residents of the home country. They also receive a transfer of some units of the foreign country currency each period. We do assume, however, that when the wealth of the representative consumer at home and abroad is assessed in terms of equilibrium prices, it is initially the same.

Individuals must pay for home goods with home currency and foreign goods with foreign currency.

Enough securities are traded (including claims to transfers), so there can be complete pooling of risk. In equilibrium, each individual will find it optimal to hold the same number of shares of all securities as anyone else. All idiosyncratic risk is perfectly diversifiable, and there is only aggregate risk in equilibrium.

A representative individual in either country maximizes at time $t$

$$
\mathrm{F}_{t} \sum_{j=0}^{\infty} \beta^{j} U\left(c_{t+j}^{0}, c_{t+j}^{1}\right)
$$

where the superscript 0 represents the home country and the superscript 1 represents the foreign country. Hence, $c^{0}$ is consumption of the good produced in the home country, and $c^{1}$ is consumption of the good produced in the foreign country.

Because felicity is homothetic, $U$ can be written as

$$
U\left(c_{t+j}^{0}, c_{t+j}^{1}\right)=V\left(h\left(c_{t+j}^{0}, c_{t+j}^{1}\right)\right),
$$

where $V^{\prime}>0, V^{\prime \prime} \leqq 0$, and $h$ is homogeneous of degree one. In turn, we can write

$$
h\left(c_{t+j}^{0}, c_{t+j}^{1}\right)=Z_{t} / P_{t}
$$

where $Z_{t}$ is total nominal expenditure in terms of the home currency:

$$
Z_{t}=P_{t}^{0} c_{t}^{0}+S_{t} P_{t}^{1} c_{t}^{1}
$$

and $P_{t}$ is a price index in terms of the home currency. Hence, we can write utility in terms of real expenditure:

$$
U\left(c_{t}^{0}, c_{t}^{1}\right)=V\left(Z_{t} / P_{t}\right)
$$

Because individuals have identical utility functions, identical initial wealth 
and there is perfect pooling of risk, all individuals make identical consumption choices and asset holding choices.

The economy-wide resource constraints are

$$
\begin{aligned}
& \varepsilon_{t}^{0}=2 c_{t}^{0}, \\
& \varepsilon_{t}^{1}=2 c_{t}^{1} .
\end{aligned}
$$

We will assume the cash-in-advance constraints are binding, so

$$
\begin{aligned}
& M_{t}^{0}=P_{t}^{0} \varepsilon_{t}^{0}, \\
& M_{t}^{1}=P_{t}^{1} \varepsilon_{t}^{1} .
\end{aligned}
$$

We have from Lucas's formula for equilibrium asset prices, using the fact that no money is paid at time $t$ for a forward contract that is settled at time $t+1$ [see Hodrick (1987, pp. 12-15) for a complete derivation]:

$$
\mathrm{E}_{t}\left(\frac{U_{0}\left(c_{t+1}^{0}, c_{t+1}^{1}\right)}{P_{t+1}^{0}}\right)\left(F_{t}-S_{t+1}\right)=0 .^{3}
$$

Then this can be rewritten as

$$
F_{t}=\frac{\mathrm{E}_{t}\left(V_{t+1}^{\prime} S_{t+1} / P_{t+1}\right)}{\mathrm{E}_{t}\left(V_{t+1}^{\prime} / P_{t+1}\right)}
$$

where we have used the fact that

$$
\frac{U_{0}}{P^{0}}=\frac{V^{\prime}}{P}
$$

We will define the risk premium, $\rho_{t} \equiv\left(\Phi_{t}-F_{t}\right) / F_{t}\left[\Phi_{t}\right.$ is defined in eq. (1)]. This definition is chosen so that positive values of $\rho_{t}$ imply that foreign assets

${ }^{3} U_{0}$ refers to the partial derivative of $U$ with respect to $c^{0}$. 
are risky, and so that the dimensions of the risk premium are in percentages comparable with rates of return. ${ }^{4}$

Note that when individuals are risk neutral, so that $V^{\prime}$ is constant in eq. (6), $F_{t}=\Phi_{t}$ and the risk premium is zero. So, contrary to the definition of the risk premium in many studies of international asset pricing [see, for example, Backus and Gregory (1989)], this definition has the desirable property that the risk premium is zero when agents are risk neutral. Define the notation $\operatorname{Scov}(x, y)$ (for 'Standardized covariance') for any two variables $x$ and $y$ as $\operatorname{Cov}(x, y) /(\mathrm{E} x \mathrm{E} y)$. We can write

$$
\rho_{t}=\frac{\operatorname{Scov}_{t}\left(V_{t+1}^{\prime}, \frac{1}{P_{t+1}}\right)-\operatorname{Scov}_{t}\left(V_{t+1}^{\prime}, \frac{S_{t+1}}{P_{t+1}}\right)}{S \operatorname{cov}_{t}\left(V_{t+1}^{\prime}, \frac{S_{t+1}}{P_{t+1}}\right)} .
$$

Examination of this expression indicates that foreign assets are less risky if $S_{t+1}$ moves together with marginal utility. This is sensible, because as $S_{t+1}$ rises, the return on foreign assets goes up. If their return tends to be high at times when marginal utility is high, then they are less risky assets.

The key observation is that marginal utility in equilibrium is a function only of real shocks, while the exchange rate is primarily a function of monetary shocks.

To see this, first note that real expenditures in equilibrium are given by

$$
Z_{\imath} / P_{t}=h\left(c_{t}^{0}, c_{l}^{1}\right)=(1 / 2) h\left(\varepsilon_{l}^{0}, \varepsilon_{l}^{1}\right)
$$

Hence, marginal utility is a function of the real shocks.

The exchange rate can also be a function of output in this model, but as Obstfeld and Stockman (1985) point out, the effects of output shocks on the exchange rate are ambiguous. Let $\alpha_{t}$ be the share of total consumption expenditure on home goods at time $t$ :

$$
\alpha_{t} \equiv P_{t}^{0} c_{t}^{0} /\left(P_{t}^{0} c_{t}^{0}+S_{t} P_{t}^{1} c_{t}^{1}\right)
$$

\footnotetext{
${ }^{4}$ The derivation of this expression for the risk premium does not rely heavily on specifics of the Lucas-type model and would hold in many discrete-time models with optimizing agents.

The continuous-time version of this expression is derived by Stulz (1981). The price index in his paper does not require homothetic preferences, but as Breeden (1979, fn. 17) explains: 'A globally valid price index that is invariant to the level of nominal expenditure exists for an individual if and only if his indifference curves are "homothetic"... The price indices used in this paper do not require that individuals be identical, nor that they have homothetic preferences. The continuity of the continuous-time framework and the weaker requirement that the price indices be locally (not globally) valid permits the greater generality of consumption preferences of this paper.'
} 
Then, we can solve out for the exchange rate from this equation, using the cash-in-advance constraints, eqs. (4) and (5), and resource constraints, eqs. (2) and (3), to get

$$
S_{t}=\frac{1-\alpha_{t}}{\alpha_{t}} \frac{P_{t}^{0} c_{t}^{0}}{P_{t}^{1} c_{t}^{1}}=\frac{1-\alpha_{t}}{\alpha_{t}} \frac{P_{t}^{0}}{P_{t}^{1}} \frac{\varepsilon_{t}^{0}}{\varepsilon_{t}^{1}}=\frac{1-\alpha_{t}}{\alpha_{t}} \frac{M_{t}^{0}}{M_{t}^{1}}
$$

If the expenditure shares are constant, exchange rates are a function only of money supplies. In general, $\alpha_{t}$ varies as income changes. It is implausible, however, that variation in expenditure shares could contribute significantly to the risk premium. Most of the studies that have examined the risk premium in Lucas-style models have assumed constant expenditure shares.

To complete the derivation of the risk premium in terms of exogenous variables, we note that $P_{t}$ can be expressed in terms of the exogenous variables as

$$
P_{t}=\frac{P_{t}^{0} V^{\prime}\left(Z_{t} / P_{t}\right)}{U_{0}}\left(\overline{c_{t}^{0}}, \frac{\left.c_{t}^{1}\right)}{1}=\left(M_{t}^{0} / \varepsilon_{t}^{0}\right) / h_{0}\left(c_{t}^{0}, \varepsilon_{t}^{1}\right) .^{5}\right.
$$

\subsection{A special case}

In this subsection special attention is given to the case in which spending shares are constant. This assumption implies, from eq. (8), that the exchange rate is a purely monetary phenomenon.

In this case the foreign exchange risk premium, from eq. (6), can be written as

$$
\rho_{t}=1-\frac{\mathrm{E}_{t} \frac{F_{t}}{P_{t+1}}}{\mathrm{E}_{t} \frac{S_{t+1}}{P_{t+1}}}=1-\frac{\mathrm{E}_{t} \frac{1}{P_{t+1}} \mathrm{E}_{t} \frac{V_{t+1}^{\prime} M_{t+1}^{0}}{P_{t+1} M_{t+1}^{1}}}{\mathrm{E}_{t} \frac{1}{P_{t+1}} \frac{M_{t+1}^{0}}{M_{t+1}^{1}} \mathrm{E}_{t} \frac{V_{t+1}^{\prime}}{P_{t+1}}}
$$

Now, noting from eq. (9) that we can write

$$
\frac{1}{P_{t+1}}=\frac{h_{0}\left(c_{t+1}^{0}, c_{t+1}^{1}\right) \varepsilon_{t+1}^{0}}{M_{t+1}^{0}}
$$

and

$$
V^{\prime} h_{0}=u_{0}
$$

${ }^{5}$ The notation $h_{0}$ refers to the partial of $h$ with respect to its first argument. 
we have

$$
\rho_{t}=1-\frac{\mathrm{E}_{t} \frac{h_{0}\left(c_{t+1}^{0}, c_{t+1}^{1}\right) \varepsilon_{t+1}^{0}}{M_{t+1}^{0}} \mathrm{E}_{t} \frac{u_{0}\left(c_{t+1}^{0}, c_{t+1}^{1}\right) \varepsilon_{t+1}^{0}}{M_{t+1}^{1}}}{\mathrm{E}_{t} \frac{h_{0}\left(c_{t+1}^{0}, c_{t+1}^{1}\right) \varepsilon_{t+1}^{0}}{M_{t+1}^{1}} \mathrm{E}_{t} \frac{u_{0}\left(c_{t+1}^{0}, c_{t+1}^{1}\right) \varepsilon_{t+1}^{0}}{M_{t+1}^{0}}}
$$

Inspection of this expression (recalling $c_{t}^{i}=0.5 \varepsilon_{t}^{i}$ ) indicates that if money supplies are independent of endowment shocks, conditional on current information, then the foreign exchange risk premium is zero.

This result is different from that of Frankel (1979). He concludes that if there were no outside bonds (an assumption which is true in the general equilibrium models we consider here) and if real income were uncorrelated with currency values, the risk premium would be zero. In terms of the model here, the latter condition is that $V^{\prime}$ be uncorrelated with $1 / P$ and $S / P$.

The result that the risk premium is zero under the assumptions that monetary and real shocks are independent, and consumption shares are constant is clearly a different result. When these assumptions are made, $V^{\prime}$ is still correlated with $1 / P$ and $S / P$. Furthermore, in general $V^{\prime}$ must be correlated with $1 / P$ and $S / P$ in this model, because the price level depends on real shocks, as does $V^{\prime}$. Frankel's conditions would imply that neither the domestic nor the foreign nominal asset is risky. The assumptions of this subsection generate a case in which domestic and foreign nominal assets are both risky, but they are equally risky.

Frankel's result is a special example of the general result that assets are not risky when their real return is uncorrelated with the marginal utility of consumption. That is not the source of the absence of a risk premium here.

Domowitz and Hakkio (1985) and Hodrick and Srivastava (1986) consider versions of the Lucas model in which expenditure shares are constant. They further assume that monetary and real shocks are independent conditional on current information. These assumptions would imply that the risk premium is zero in their models. ${ }^{6}$ Thus, the behavior of the variable that they define as the foreign exchange risk premium, $F_{t}-\mathrm{E}_{t} S_{t+1}$, is not determined at all by risk considerations.

Several other studies of the foreign exchange risk premium in general equilibrium cash-in-advance models also assume independent monetary and real shocks. These include Hodrick (1989a), Kaminsky and Peruga (1988),

\footnotetext{
${ }^{6}$ As noted in section 2 , there is another reason why the risk premium would be zero - they assume risk-meutral investors. The point here is that even if one assumed utility was a concave transformation of the utility functions assumed by these authors, so their investors were risk averse, the risk premium would still be zero.

Note that much of the discussion in Hodrick and Srivastava does not focus on the relation of the forward premium to exogenous variables, and hence is immune to the criticisms raised here.
} 
and Canova and Marrinan (1990). These papers contrast with the general equilibrium studies of Stulz (1984) and Sibert (1989), which are in very different frameworks from the Lucas approach, but which explicitly stress the importance of the covariance of monetary and real shocks. It is clear that their findings extend to the Lucas-style model.

\section{Conclusions}

If consumers have constant relative risk aversion and constant expenditure shares, a Taylor series approximation of eq. (7) is given by (see the appendix for the derivation of this approximation):

$$
\rho_{t}=\eta\left[\alpha\left(\sigma_{n^{0} \mu^{0}}-\sigma_{n^{0} \mu^{1}}\right)-(1-\alpha)\left(\sigma_{n^{1} \mu^{1}}-\sigma_{n^{1} \mu^{0}}\right)\right] .
$$

In this expression, $\eta$ is the constant of relative risk aversion, $\alpha$ is the share spent on home goods, and the $\sigma$ 's are conditional covariances between rates of growth of output and money. Output growth is signified by $n$, and money growth by $\mu$, with the superscripts indicating the relevant country $(0$ for home and 1 for foreign). The expression shows that foreign assets are relatively risky when the covariance between home money growth and output growth of either country is high relative to the covariance between foreign money growth and output growth of either country.

This expression is very similar to eq. (34) of Stulz (1984), if one assumes, as in Stulz, that $\eta=1$ and $\sigma_{n^{0} \mu^{1}}=\sigma_{n^{1} \mu^{0}}=0$. Stulz's model is in a continuous time framework, and assumes real money balances are arguments of the utility function. This suggests that the dependence of the risk premium primarily on the covariance of real and monetary shocks is a robust result.?

Both types of models produce risk premiums that are roughly of the same order of magnitude as the covariance of rates of growth of money and output. Can these models generate risk premiums similar to the return differentials observed in the data?

The actual value of $\rho_{t}$ in the data is not a number that is known to economists, because, as eq. (7) indicates, it is a function of conditional expectations of exchange rates and prices. The conditional expectations of market participants is unobservable, but there have been numerous econometric attempts to measure $\rho$ econometrically. These measures for the dollar against major currencies indicate very large values of $\rho_{t}$ - on the order of a risk premium on the dollar of 1.5-2 percentage points on a quarterly basis for the entire 1980-1985 period, and then an equally large risk premium on foreign currencies for the 1985-1987 period [see Engel and Hamilton (1990,

\footnotetext{
${ }^{7}$ Sibert (1989) is an overlapping generations model in which saving must be done in domestic or foreign currencies. Sibert also emphasizes the importance of the covariance of monetary and real shocks. This result can also be obtained from Boyle (1990).
} 
table 7); Frankel and Froot (1987) and Froot (1990) estimate that the return differentials are about twice this size]. This translates to conditional risk premiums on the order of $6-8$ percentage points at annual rates.

It should be noted that these rough measures of the risk premiums were calculated using nominal data. In empirical work, expressing the risk premium in real terms seems to make almost no difference in measures of the magnitude of the risk premium in percentage terms, or in strength of rejection of the null of risk neutrality and efficiency. Stockman (1978, p. 166) says that one may ignore the difference for empirical purposes. This has been confirmed by Frenkel and Razin (1980), Engel (1984) and Hodrick (1989b). It is interesting that the coefficient estimates in Hodrick's regression for the risk premium defined here match up closely to the estimates discussed by Froot (1990). In particular, regressions of $\log \left(s_{t+1}\right)-\log \left(F_{t}\right)$ (as in Froot) and $\left(S_{t+1}-F_{t}\right) P_{t} / P_{t+1} S_{t}$ (which is Hodrick's dependent variable) on the forward premium both consistently yield a coefficient estimate around -1 . Undoubtedly the reason deflating by nominal prices makes so little difference in empirical practice is that nominal prices have been far less variable than nominal exchange rates [see Mussa (1986)]. However, a careful measurement of the size of the risk premium (which takes into account, for example, the role of durable goods) has not been undertaken, so the approximation of the size of the risk premium as $6-8$ percentage points must be treated with some caution.

Backus, Gregory and Telmer (1990) and Hakkio and Sibert (1990) are recent papers which simulate general equilibrium monetary models. They both find that these models generate very small risk premiums (as much as two orders of magnitude too small) when an agent's behavior is based on expected utility maximization with time-separable preferences.

A similar exercise could be undertaken with the Lucas model, but a quick common-sense check reveals that such an effort would be fruitless, because the covariance of money and output growth rates for industrialized nations in the 1980 s is likely to be much too small to explain return differentials on the order of $6-8$ percentage points. ${ }^{8}$

Suppose we make the following assumptions, which are the most favorably biased possible, toward finding a large risk premium:

$$
\begin{aligned}
& \operatorname{corr}\left(\mu^{0}, n^{0}\right)=1, \\
& \operatorname{corr}\left(\mu^{1}, n^{1}\right)=-1, \\
& \operatorname{corr}\left(\mu^{0}, n^{1}\right)=1,
\end{aligned}
$$

\footnotetext{
${ }^{8}$ Indeed, Macklem (1990) has recently simulated a version of the Lucas model, and confirms that the risk premiums it produces are much too small.
} 
$\operatorname{corr}\left(\mu^{1}, n^{0}\right)=-1$

where 'corr' refers to the correlation coefficient. Notice that this favorable case requires that the correlations between output and money at home be exactly the opposite of the correlations abroad. As the correlations become more similar, the risk premium goes to zero.

In addition, let us assume a very large value for the coefficient of risk aversion, $\eta=10$. Now if, for convenience, we assume the (conditional) standard deviations of home and domestic money growth and output growth are all equal, we conclude that in this most extreme case we still need implausibly large conditional standard deviations of money and output growth of 6 percentage points! ${ }^{9}$

Eq. (11) is simple enough that the reader can easily plug in her own estimates of these covariances, and she will likely find that the predicted risk premium is about two orders of magnitude smaller than the return differential that needs to be explained. ${ }^{10}$ The reason for this is that the risk premium in the Lucas model is probably no larger (and maybe much smaller) than the covariances of real and money growth rates, and these are quite small.

\section{Appendix}

This appendix outlines the derivation of eq. (11). Note that eq. (10) may be written as (where $\xi=1-\eta$ )

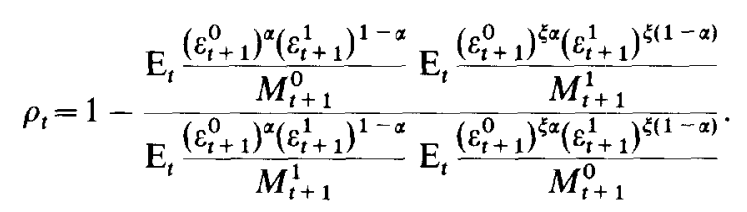

Dividing through top and bottom by $\left[\left(\varepsilon_{t}^{0}\right)^{\alpha}\left(\varepsilon_{t}^{1}\right)^{1-\alpha}\right]^{\xi+1} / M_{t}^{0} M_{t}^{1}$, we have

$$
\rho_{t}=1-\frac{\mathrm{E}_{t} \frac{\left(1+n^{0}\right)^{\alpha}\left(1+n^{1}\right)^{1-\alpha}}{1+\mu^{0}}-\mathrm{E}_{t} \frac{\left(1+n^{0}\right)^{\xi \alpha}\left(1+n^{1}\right)^{\xi(1-\alpha)}}{1+\mu^{1}}}{\mathrm{E}_{t} \frac{\left(1+n^{0}\right)^{\alpha}\left(1+n^{1}\right)^{1-\alpha}}{1+\mu^{1}} \mathrm{E}_{t} \frac{\left(1+n^{0}\right)^{\xi \alpha}\left(1+n^{1}\right)^{\xi(1-\alpha)}}{1+\mu^{0}}},
$$

\footnotetext{
${ }^{9}$ This would imply 95 percent confidence intervals of about \pm 12 percentage points.

${ }^{10}$ Backus, Gregory and Telmer (1990) find that they can produce larger risk premiums from general equilibrium models when preferences exhibit habit persistence, and hence are not time separable.
} 
where the time subscripts on $\mu^{0}, \mu^{1}, n^{0}$ and $n^{1}$ have been dropped for convenience.

If we take a second-order Taylor series expansion around $\mu^{0}=\mu^{1}=n^{0}=$ $n^{1}=0$ for each of the four non-linear expressions whose conditional expectations are taken in (A.1), and then take expectations, we get, for example,

$$
\begin{aligned}
\mathrm{E}_{t} \frac{\left(1+n^{0}\right)^{\alpha}\left(1+n^{1}\right)^{1-\alpha}}{1+\mu^{0}}= & 1+\alpha \bar{n}^{0}+(1-\alpha) \bar{n}^{1}-\bar{\mu}^{0}-\bar{\mu}^{1}-0.5 \alpha(1-\alpha)\left(\sigma_{n^{0}}^{2}+\sigma_{n^{1}}^{2}\right) \\
& +\sigma_{\mu^{0}}^{2}+\alpha(1-\alpha) \sigma_{n^{0} n^{1}}-\alpha \sigma_{n^{0} \mu^{0}}-(1-\alpha) \sigma_{n^{1} \mu^{0}} . \quad \text { (A.3) }
\end{aligned}
$$

In this expression an overbar refers to the conditional mean of a variable, $\sigma$ refers to a covariance, and $\sigma^{2}$ is a variance. The Taylor series expansions for the other three expectations are analogous.

In the above expression we have used the fact that the squares and crossproducts of the conditional means are approximately zero, which allowed us to write the expectations of squares and cross-products as variances and covariances. Indeed, following Merton (1969), the squares and cross-products of the means, covariances, and variances are all second order, so, if $a, b, c$ and $d$ are sums of means, covariances and variances, we have that $(1+a)(+b) /(1+c)(1+d) \cong 1+a+b-c-d$.

Applying this approximation yields eq. (11) in the text.

\section{References}

Backus, D. and A. Gregory, 1989, Risk premiums in asset prices and returns: A comment on R.T. Baillie, 'Econometric tests of rationality and market efficiency', Econometric Reviews 8, 187-195.

Backus, D., A. Gregory and C. Telmer, 1990, Accounting for forward rates in markets for foreign currency, Manuscript, Federal Reserve Bank of Minneapolis.

Boyer, R., 1977, The relation between the forward exchange rate and the expected future spot rate, Intermountain Economic Review 8, 14-21.

Boyle, G., 1990, International interest rates, exchange rates, and the stochastic structure of supply, Journal of Finance 45, 655-671.

Breeden, D., 1979, An intertemporal asset pricing model with stochastic consumption and investment opportunities, Journal of Financial Economics 7, 265-296.

Canova, F. and J. Marrinan, 1990, Nominal profits, risk and uncertainty in foreign exchange markets, Manuscript, Brown University.

Domowitz, I. and C. Hakkio, 1985, Conditional variance and the risk premium in the foreign exchange market, Journal of International Economics 19, 47-66.

Engel, C., 1984, Testing for the absence of expected real profits from forward market speculation, Journal of International Economics 17, 299-308.

Engel, C. and J. Hamilton, 1990, Long swings in the dollar: Are they in the data and do markets know it? American Economic Review 80, 689-713.

Frankel, J., 1979, The diversifiability of exchange risk, Journal of International Economics 9, 379-393.

Frankel, J. and K. Froot, 1987, Using survey data to test standard propositions on exchange rate expectations, American Economic Review 77, 133-153. 
Frenkel, J. and A. Razin, 1980, Stochastic prices and tests of efficiency of foreign exchange markets, Economics Letters 6, 165-170.

Froot, K., 1990, On the efficiency of foreign exchange markets, Manuscript, M.I.T.

Hakkio, C. and A. Sibert, 1990, An equilibrium model of spot and forward exchange rates, Working paper, Federal Reserve Bank of Kansas City.

Hodrick, R., 1987, The empirical evidence on the efficiency of forward and futures foreign exchange markets (Harwood Academic Publishers, Chur).

Hodrick, R., 1989a, Risk, uncertainty and exchange rates, Journal of Monetary Economics 23, 433459.

Hodrick, R., 1989b, U.S. international capital flows: Perspectives from rational maximizing models, Carnegie-Rochester Conference Series on Public Policy 30, 231-288.

Hodrick, R. and S. Srivastava, 1986, The covariation of risk premiums and expected future spot rates, Journal of International Money and Finance 5, S5-S21.

Kaminsky, G. and R. Peruga, 1988, Credibility crises: The dollar in the early eighties, Journal of International Money and Finance 10, 170-192.

Krugman, P., 1977, Essays in flexible exchange rates, Ph.D. dissertation, Massachusetts Institute of Technology.

Lucas, R., 1982, Interest rates and currency prices in a two-country world, Journal of Monetary Economics 10, 335-360.

Macklem, R.T., 1990, Forward exchange rates and risk premiums in artificial economies, Journal of International Money and Finance 10, 365-391.

Merton, R., 1969, Lifetime portfolio selection under uncertainty: The continuous-time case, The Review of Economics and Statistics 51, 247-257.

Mussa, M., 1986, Nominal exchange rate regimes and the behavior of real exchange rates: Evidence and implications, Carnegie-Rochester Series on Public Policy 25, 117-213.

Obstfeld, M. and A. Stockman, 1985, Exchange rate dynamics, in: Ronald Jones and Peter Kenen, eds., Handbook of international economics, Vol. 2 (North-Holland, Amsterdam).

Sibert, A., 1989, The risk premium in the foreign exchange market, Journal of Money, Credit and Banking 21, 49-65.

Stiglitz, J., 1969, Behavior towards risk with many commodities, Econometrica 37, 660-667.

Stockman, A., 1978, Risk, information and forward exchange rates, in: J. Frenkel and H. Johnson, eds., The economics of exchange rates (Addison-Wesley, Reading, MA).

Stulz, R., 1981, A model of international asset pricing, Journal of Financial Economics 9, 383-406.

Stulz, R., 1984, Currency preferences, purchasing power risks, and the determination of exchange rates in an optimizing model, Journal of Money, Credit and Banking 16, 302-316.

Svensson, L.E.O., 1985a, Currency prices, terms of trade, and interest rates: A general equilibrium asset-pricing cash-in-advance approach. Journal of International Economics 18, $17-41$.

Svensson, L.E.O., 1985b, Money and asset prices in a cash-in-advance economy, Journal of Political Economy 93, 919-944. 